\title{
Preparation of Novel Chitosan-Starch Blends as Thickening Agent and Their Application in Textile Printing
}

\author{
E. S. Abdou, ${ }^{1}$ H. M. El-Hennawi, ${ }^{2}$ and K. A. Ahmed ${ }^{2}$ \\ ${ }^{1}$ Chemistry Department, Faculty of Science and Humanities, Salman Bin Abdualaziz University, 11941, Saudi Arabia \\ ${ }^{2}$ Chemistry of Dyeing, Printing and Auxiliaries Department, Textile Division, National Research Center, Cairo, Egypt
}

Correspondence should be addressed to K. A. Ahmed; kawther_zaher@yahoo.com

Received 19 December 2011; Revised 15 May 2012; Accepted 21 May 2012

Academic Editor: Tomokazu Yoshimura

Copyright (C) 2013 E. S. Abdou et al. This is an open access article distributed under the Creative Commons Attribution License, which permits unrestricted use, distribution, and reproduction in any medium, provided the original work is properly cited.

\begin{abstract}
Chitosan, a naturally available biopolymer which is now increasingly used as a functional finish on textile substrates to impart antimicrobial characteristics and increase dye uptake of fabrics, was blended with different ratios of gelatinized starch. The chitosan was extracted and characterized by IR, ${ }^{1} \mathrm{H}-\mathrm{NMR}$, and X-ray powder diffraction. These blends were tested as thickeners in textile screen printing using Curcuma tinctoria as natural dye. The rheological properties and the viscosity of the printing paste were measured. The effect of chitosan on the printing properties of different fabrics (natural, blends, and synthetic fabrics) was studied by measuring the color strength value $(\mathrm{K} / \mathrm{S})$ and related color parameters of the printed fabrics. The antimicrobial properties of printed fabrics were assessed. The results proved that the printed fabrics using these new thickeners showed increase in the color strength value $(\mathrm{K} / \mathrm{S})$ giving darker color which means that chitosan increased the dye uptake on fabrics. Fastness properties of the printed fabrics to washing, rubbing, perspiration, and light have also been improved. The treated fabrics were found to be antimicrobial.
\end{abstract}

\section{Introduction}

Improving the environmental impact and unifying processes as a result of using one class of dyes in coloring fabrics made of blends of chemical and natural fibers is one of the main trends in the evolution of textile dyeing and printing technology.

Recently, there has been a revival of interest in natural dyes throughout the world as some synthetic dyes are being banned due to their toxic, carcinogenic, and polluting nature. Most natural dyes need the use of chemicals, called mordant, to help promoting dye absorption and fixing and prevent bleeding and fading of the colors. Mordants form chemical bonds between the dye molecules and the proteins of the fabrics (wool is generally the best fabric colored with natural dyes).

Natural dyes are used for food coloring, painting, and textile dyeing $[1,2]$. They have shown a greater interest in textile dyeing because they are more ecofriendly than synthetic dyes. Curcumin (1,7-bis(4-hydroxy-3-methoxy phenyl)-1,6heptadione-3,5-dione) is a yellow pigment present in rhizome of Curcuma longa which is widely used in food industry [3].

Treatment of textiles with chitosan which is considered as multifunctional finish not only contributes to its antimicrobial properties but also results in enhancement of color strength thus generating much interest towards chitosan [46]. It is also used as an auxiliary in printing of textiles. It has been reported that the printed samples have comparable color fastness to that of commercial printed samples, but chitosan film on fabric surface is not desirable since it causes the problem of fabric stiffness (poor handling) $[7,8]$.

Blending of starch with chitosan results in formation of edible coating with a good film forming and mechanical properties [9]; starch must be gelatinized first before blending with chitosan. Hence the aim of the present study is to investigate the combined effect of chitosan and gelatinized 
starch as thickening agent in screen printing technique using natural dye and to explore its antimicrobial properties.

\section{Materials and Methods}

\subsection{Materials}

\subsubsection{Soluble Starch Was Obtained from Fluka} Chemical Company

\subsubsection{Curcuma tinctoria Was Purchased from the} Local Market

2.1.3. High Viscosity Sodium Alginate from Brown Algae, Manufactured by (Fluka Chemical Company), Was Used as a Thickening Agent

\subsubsection{Fabric}

(i) Cotton: mill desized, bleached, and mercerized cotton fabrics $\left(130 \mathrm{~g} / \mathrm{m}^{2}\right)$ produced by Misr/Helwan for Spinning and Weaving Company, Egypt.

(ii) Wool: mill scoured wool fabric (100\%) supplied by Misr Co. for Spinning and Weaving, Mehalla ElKubra, Egypt.

(iii) Nylon: nylon-6 fabric produced by El-Shourbagy Co. Cairo, Egypt.

(iv) Polyester: polyester- (PE-) knitted fabric of $150 \mathrm{~g} / \mathrm{m}^{2}$, supplied by a private sector company which was treated with a solution containing $1 \mathrm{~g} / \mathrm{L}$ nonionic detergent at $70^{\circ} \mathrm{C}$ for $1 / 2 \mathrm{~h}$, thoroughly washed, and air-dried at room temperature.

(v) Blend fabrics: different kinds of blended fabrics comprise viscose/polyester (80/20) and cotton/polyester $(60 / 40)$ were also used.

\subsection{Methods}

2.2.1. Extraction of Chitosan. Chitosan was extracted frommarine shrimp shells. The exoskeletons of the shrimps were crushed and treated in the usual way with $\mathrm{HCl}, \mathrm{NaOH} 1-$ $2 \mathrm{M}$ then with $40 \% \mathrm{NaOH}$ to extract the chitosan [10]. Chitosan was characterized using the Fourier transform infrared (FTIR) spectroscopy, ${ }^{1} \mathrm{H}-\mathrm{NMR}$ spectroscopy, and Xray powder diffraction.

The degree of deacetylation (DDA\%) of chitosan determined by potentiometric titration [11], and the molecular weight was calculated using the value of intrinsic viscosity [12], measured by an Ubbelohde viscometer. The value of (DDA\%) and molecular weight of chitosan were $85 \%$ and $11.44 \times 10^{4} \mathrm{gm} / \mathrm{mol}$, respectively.
2.2.2. Characterization of Prepared Chitosan. The Fourier Transform Infrared (FTIR) Spectroscopy. The FTIR spectra were measured in $\mathrm{KBr}$ pellets in the transmission mode in the range $400-7000 \mathrm{~cm}^{-1}$ using Perkin-Elmer $2000 \mathrm{spec}-$ trophotometer. ${ }^{1} H$-NMR Spectra. Nuclear magnetic resonance ${ }^{1} \mathrm{H}-\mathrm{NMR}$ spectra were measured using JNMAl 300; Jeol spectrometer at $300 \mathrm{MHz}$ in $\mathrm{D}_{2} \mathrm{O}$ in which drops of $\mathrm{DCl}$ was added to enhance solubility. X-Ray Diffraction. Xray diffraction analysis (XRD) was applied to detect the crystallinity of the extracted samples of chitin and their corresponding chitosan. A Scintag powder diffractometer was used for this purpose between $2 \theta$ angles of $5^{\circ}$ and $40^{\circ}$. Ni-filtered $\mathrm{Cu} \mathrm{K} \alpha$-radiation was used as the X-ray source. The relative crystallinity of the polymers was calculated by dividing the area of the crystalline peaks by the total area under the curve.

2.2.3. Gelatinization of Starch Solution in Microwave. Starch was gelatinized first in microwave before blending with chitosan. Starch samples with predetermined starch concentrations, were prepared by using soluble starch and distilled water, and the samples were stirred gently just before heating them in the microwave oven in order to ensure that the starch was fully suspended in the water. The starch ratio in the prepared samples was 3, 4, 5, and 6\%. Then starch samples $(150 \mathrm{~mL})$ were heated at full power in the microwave oven WP800 for 2 minutes.

2.2.4. Blend Formation. Chitosan was blended with all the prepared gelatinized starch with fixed ratio $1 \%$ of the starch samples.

2.2.5. Preparation of Printing Paste. The suitability of chitosan and gelatinized starch blends as thickening agents in screen printing technique was investigated using Curcuma tinctoria as natural dye. To achieve this goal, different printing paste using the new thickeners and another one with sodium alginate as thickening agent for the sake of comparison were prepared according to the recipe givenin Table 1 .

Sodium alginate was first soaked in small amount of water overnight at room temperature before preparing the printing paste. The natural color and urea were then added on the thickener suspension as in the recipe mention then the total weight of the whole paste was adjusted to one kilogram with the addition of the necessary amount of water. All the printed samples except the wool samples were fixed via thermofixation at $160^{\circ} \mathrm{C}$ for $5 \mathrm{~min}$. The wool printed samples were fixed by steaming at $100^{\circ} \mathrm{C}$ for $10 \mathrm{~min}$ after fixation the printed samples were washed as follows.

(i) Washing with cold running water.

(ii) Soaping (using $2 \mathrm{~g} / \mathrm{L}$ nonionic detergent namely Espycon 1030) at $45^{\circ} \mathrm{C}$ for 15 minutes.

(iii) Rinsing with cold water.

At this end the printed fabrics were dried and assessed for color strength value (K/S) and over all fastness properties. 
TABLE 1

\begin{tabular}{lc}
\hline $\begin{array}{l}\text { Thickening agent } \\
\text { (Sod.alginate suspension or chitosan-starch } \\
\text { blends) }\end{array}$ & $500 \mathrm{~g}$ \\
Curcuma tinctoria & $30 \mathrm{~g}$ \\
Urea & $100 \mathrm{~g}$ \\
Water & $370 \mathrm{~g}$ \\
\hline & $1000 \mathrm{~g}$ \\
\hline
\end{tabular}

2.2.6. Rheological Properties. Rheological properties of chitosan/gelatinous-starch blends were studied using Brookfield Digital Rheometer, model HA DVIII Ultra (Brookfield Engineering Laboratories INC.), with spindle no. SC4-21 [13]. The rheological parameters for starchchitosan blends were measured at room temperature.

2.2.7. Determination of Color Strength and Related Parameters. The color strength of the printed samples was evaluated by Hunter Lab Ultra scan PRO. at $\lambda_{\max }$.

The color difference and relative color strength \% between chitosan/starch printed samples and control samples were also obtained using the following relationships.

Relative color strength $(\%)=(\mathrm{K} / \mathrm{S}$ of chitosan $/$ starch blend $) /(\mathrm{K} / \mathrm{S}$ of control sample $) \times 100$ :

$$
\Delta E=\sqrt{(\Delta L)^{2}+(\Delta a)^{2}+(\Delta b)^{2}}
$$

where $\Delta L=L-L^{*} ; \quad \Delta a=a-a^{*} ; \quad \Delta b=b-b^{*}$.

" $L$ " describes lightness; " $a$ " measures redness or greenness " $b$ " measures yellowness or blueness; where $L^{*}, a^{*}$, and $b^{*}$ are color parameters of control sample.

2.2.8. Determination of Fastness Properties. The treated samples were washed as per the conditions specified in the test AATCC test method [14]. The color fastness to rubbing, perspiration, and light was determined according to the AATCC test methods [15-17].

2.2.9. Antibacterial Activity. The Antibacterial activity was assayed in the Microanalytical Centre of Cairo University using Kirby-Bauer disc diffusion method [18].

\section{Results and Discussion}

3.1. FTIR Spectra. The FTIR spectra of chitosan represent a characteristic band at $3424 \mathrm{~cm}^{-1}$ which is attributed to $-\mathrm{NH}_{2}$ and $-\mathrm{OH}$ groups stretching vibration, the band for amide at $1654 \mathrm{~cm}^{-1}$, and the aliphatic $\mathrm{C}-\mathrm{H}$ stretching between 2921 and $2876 \mathrm{~cm}^{-} 1$, When starch and chitosan are mixed, physical blends versus chemical interactions are reflected by changes in characteristic spectra peaks In the typical spectrum of chitosan/starch composite film, the amino peak of chitosan shifted from 1578 to $1584 \mathrm{~cm}^{-1}$ with the addition of starch). This result indicated that interactions were present between the hydroxyl groups of starch and the amino groups of chitosan $[19,20]$.

3.2. ${ }^{1} H$-NMR Method. The chemical shift of methyl protons in acetamide group to appear at $2.07 \mathrm{ppm}$ in acidic deuterium oxide solutions while the methyl group of glacial acetic acid appears at $2.12 \mathrm{ppm}$ (The Aldrich Library of NMR Spectra). Therefore, the peak around $2.1 \mathrm{ppm}$ can be safely assigned to the methyl protons in the acetamide group, and that around $2.2 \mathrm{ppm}$ is due to the methyl group in acetic acid moiety. The chemical shift is affected by solvent type, concentration and temperature, and taking these into account, one can explain the difference between the chemical shift value reported by Shen et al. [21], and those reported here.

In the obtained spectra, the difference in chemical shifts between peaks at about 2.1 and $2.2 \mathrm{ppm}$ is constant (about $0.15 \mathrm{ppm}$ ) within the experimental errors. The setting of TMS peak to be $0 \mathrm{ppm}$ is sometimes slightly affected by operational and spectral variations, and for peaks with many "spikes" as in our case, the reproducibility might be lowered. Therefore, it can be safely stated that the chemical shift for amide methyl protons can be set to $2.06 \mathrm{ppm}$ and that for acetic acid moiety to $2.21 \mathrm{ppm}$.

3.3. X-Ray Diffraction. X-ray diffraction (XRD) analysis was applied to detect the crystallinity of the isolated chitin and the obtained chitosan The structure of $\alpha$-chitin has been determined [22] using X-ray diffraction analysis, based on the intensity data from deproteinized lobster tendon. Least-squares refinement shows that adjacent chains have alternating sense (i.e., are antiparallel). In addition, there is a statistical distribution of side chain orientations, such that all the hydroxyl groups form hydrogen bonds. The unit cell is orthorhombic.

The chains form hydrogen bonded sheets linked by $\mathrm{C}=\mathrm{O} \cdots \mathrm{H}---\mathrm{N}$ bonds approximately parallel to the $a$-axis, and each chain has an $\mathrm{O}-3^{\prime}$ - - - H . . O.5 intramolecular hydrogen bond, similar to that in cellulose. The results indicate also that a statistical mixture of $\mathrm{CH}_{2} \mathrm{OH}$ orientations is present, equivalent to half oxygen on each residue, each forming interand intramolecular hydrogen bonds. As a result, the structure contains two types of amide groups, which differ in their hydrogen bonding, and account for the splitting of the amide I band in the infrared spectrum. The inability of this chitin polymorph to swell on soaking in water is explained by the extensive intermolecular hydrogen bonding.

3.4. Rheological Properties. The rheological behavior of the printing paste plays one of the most important roles in the process of textile printing because it affects the amount of printing paste applied on the textile surface and consequently on the quality of the printed substrate. Hence, pastes of the aforementioned blends were prepared and the rheological properties of the pastes were monitored before and after storing of the pastes for $24 \mathrm{~h}$. The results obtained are shown in Figures 1 and 2.

The rheograms reveal that all the pastes under investigation display non-Newtonian pseudoplastic behavior since 
TABLE 2: Effect of starch concentration on the apparent viscosity at various rate of shear for freshly prepared pastes.

\begin{tabular}{|c|c|c|c|c|}
\hline \multirow{2}{*}{ Rate of shear $\left(\sec ^{-1}\right)$} & \multicolumn{4}{|c|}{ Apparent viscosity } \\
\hline & $3 \%$ starch & $4 \%$ starch & $5 \%$ starch & $6 \%$ starch \\
\hline 9.3 & 190 & 250 & 430 & 820 \\
\hline 18.6 & 180 & 240 & 415 & 760 \\
\hline 27.9 & 173.3 & 236.7 & 406.7 & 730 \\
\hline 37.2 & 166 & 230 & 395 & 700 \\
\hline 46.5 & 161.7 & 226 & 386 & 672 \\
\hline 55.8 & 160 & 223.3 & 378.3 & 651 \\
\hline 65.1 & 155 & 220 & 368.6 & 634.3 \\
\hline 74.4 & 153.3 & 217.5 & 361.2 & 616.2 \\
\hline 83.7 & 152 & 214.4 & 354.4 & 601.1 \\
\hline 93 & 152 & 212 & 347 & 587 \\
\hline 93 & 152.2 & 210 & 349 & 587 \\
\hline 83.7 & 152.5 & 212.2 & 348 & 600 \\
\hline 74.4 & 152.9 & 215 & 352.5 & 617.5 \\
\hline 65.7 & 155 & 217.1 & 358.6 & 634.3 \\
\hline 55.8 & 155 & 220 & 365 & 655 \\
\hline 46.5 & 156 & 222 & 370 & 660 \\
\hline 27.9 & 157.5 & 225 & 380 & 710 \\
\hline 37.2 & 158.7 & 230 & 390 & 750 \\
\hline 18.6 & 160 & 235 & 400 & 795 \\
\hline 9.3 & 163 & 240 & 410 & 870 \\
\hline
\end{tabular}

TABLE 3: Effect of starch concentration on the apparent viscosity at various rate of shear for prepared pastes after storing 24 hours.

\begin{tabular}{|c|c|c|c|c|}
\hline \multirow{2}{*}{ Rate of shear $\left(\sec ^{-1}\right)$} & \multicolumn{4}{|c|}{ Apparent viscosity } \\
\hline & $3 \%$ starch & $4 \%$ starch & $5 \%$ starch & $6 \%$ starch \\
\hline 9.3 & 150 & 260 & 500 & 1070 \\
\hline 18.6 & 145 & 243 & 475 & 955 \\
\hline 27.9 & 140 & 236.7 & 458.7 & 903.3 \\
\hline 37.2 & 140 & 230 & 442.5 & 890 \\
\hline 46.5 & 130 & 226 & 428 & 864 \\
\hline 55.8 & 136.7 & 221.7 & 418 & 850 \\
\hline 65.1 & 135.7 & 218.6 & 408.6 & 840 \\
\hline 74.4 & 133.7 & 215 & 400 & 853 \\
\hline 83.7 & 133.7 & 212.2 & 392.2 & 830.8 \\
\hline 93 & 133 & 210 & 386 & 814 \\
\hline 93 & 132. & 210 & 385 & 802 \\
\hline 83.7 & 132.2 & 212.2 & 391.1 & 822.2 \\
\hline 74.4 & 132.5 & 215 & 398.7 & 825 \\
\hline 65.1 & 132.9 & 217.1 & 407 & 788 \\
\hline 55.8 & 133.3 & 221.7 & 416.7 & 765 \\
\hline 46.7 & 136 & 224 & 426 & 750 \\
\hline 27.9 & 137.5 & 230 & 137.5 & 787.5 \\
\hline 37.2 & 136.7 & 233.3 & 453.3 & 833 \\
\hline 18.6 & 140 & 240 & 470 & 905 \\
\hline 9.3 & 150 & 250 & 500 & 1010 \\
\hline
\end{tabular}


TABLE 4: The K/S, relative color strength \% of Curcuma tinctoria printed samples.

\begin{tabular}{lcccccccccccc}
\hline \multirow{2}{*}{ Thickener used } & \multicolumn{1}{c}{ Cotton } & \multicolumn{1}{c}{ Cotton/polyester } & \multicolumn{4}{c}{ Colyester } & \multicolumn{2}{c}{ Viscose/polyester } & \multicolumn{2}{c}{ Polyamide } \\
& K/S & \% K/S & K/S & \% K/S & K/S & \% K/S & K/S & \% K/S & K/S & $\%$ K/S & K/S & $\%$ K/S \\
\hline Sod. alginate & 3.88 & 100 & 1.91 & 100 & 0.98 & 100 & 4.24 & 100 & 1.44 & 100 & 2.01 & 100 \\
3\% starch & 6.46 & 167 & 7.45 & 390 & 5.01 & 511 & 8.15 & 192 & 5.74 & 399 & 9 & 474 \\
4\% starch & 9.61 & 248 & 11.42 & 598 & 5.04 & 514 & 7.92 & 187 & 7.04 & 488 & 8.12 & 404 \\
5\% starch & 7.94 & 205 & 5.93 & 311 & 5.12 & 523 & 7.06 & 167 & 7.94 & 551 & 6.57 & 327 \\
6\% starch & 5.81 & 150 & 3.48 & 182 & 4.97 & 201 & 6.97 & 164 & 6.32 & 439 & 5.66 & 282 \\
\hline
\end{tabular}

TABLE 5: Color parameter and the color difference of printed Fabrics.

\begin{tabular}{lcccccccccccc}
\hline Printed sample & $L^{*}$ & $a^{*}$ & $b^{*}$ & $L$ & $a$ & $b$ & $\Delta L$ & $\Delta a$ & $\Delta b$ & $\Delta E$ & $C_{a^{*} b^{*}} C_{a b}$ \\
\hline Wool & 76.22 & -1.85 & 47.68 & 63.53 & 9.72 & 55.63 & -12.69 & 11.57 & 7.95 & 50.83 & 47.7 & 56.4 \\
Polyamide & 67.42 & -4.44 & 16.29 & 64.53 & -5.56 & 57.30 & -2.96 & 1.12 & 41.01 & 41.13 & 16.8 & 17.7 \\
Polyester & 83.96 & -7.36 & 15.39 & 74.03 & -5.39 & 63.21 & -9.93 & 1.97 & 47.82 & 48.88 & 17.0 & 63.4 \\
Cotton/polyester & 77.81 & -2.16 & 41.39 & 67.50 & 11.48 & 49.02 & -10.31 & 13.46 & 7.81 & 18.66 & 41.4 & 50.3 \\
Cotton & 85.15 & -4.14 & 13.6 & 70.54 & 6.64 & 62.82 & -14.61 & 10.78 & 49.22 & 51.71 & 14.2 & 63.1 \\
Viscose/polyester & 80.91 & -4.93 & 22.02 & 72.63 & 2.38 & 58.51 & -8.28 & 7.31 & 36.49 & 38.13 & 22.5 & 58.5 \\
\hline
\end{tabular}

TABLE 6: Fastness properties of control and highest K/S samples and surface roughness of fabrics.

\begin{tabular}{|c|c|c|c|c|c|c|c|c|c|c|}
\hline \multirow{3}{*}{ Printing paste } & \multicolumn{2}{|c|}{ Rubbing fastness } & \multicolumn{2}{|c|}{ Washing fastness } & \multicolumn{4}{|c|}{ Perspiration fastness } & \multirow{3}{*}{ Light fastness } & \multirow{3}{*}{ Roughness } \\
\hline & \multirow{2}{*}{ Dry } & \multirow{2}{*}{ Wet } & \multirow{2}{*}{ Alt. } & \multirow{2}{*}{ St. } & \multicolumn{2}{|c|}{ Acid } & \multicolumn{2}{|c|}{ Alkaline } & & \\
\hline & & & & & Alt. & St. & Alt & St. & & \\
\hline \multicolumn{11}{|c|}{ Cotton fabric $(100 \%)$} \\
\hline Commercial paste & $4-5$ & 4 & 4 & 4 & 4 & $4-5$ & 4 & 4 & 1 & 13.01 \\
\hline $5 \%$ starch/chitosan & $4-5$ & 3 & 4 & 4 & 4 & $4-5$ & 4 & 4 & 3 & 13.11 \\
\hline \multicolumn{11}{|c|}{ Cotton/polyester blend fabric $(35 / 65)$} \\
\hline Commercial paste & $4-5$ & $4-5$ & 4 & 4 & 4 & 4 & 4 & 4 & 1 & 16.78 \\
\hline $6 \%$ starch/chitosan & $4-5$ & 4 & 4 & 4 & 4 & 4 & 4 & 4 & $3-4$ & 12.17 \\
\hline \multicolumn{11}{|c|}{ Viscose/polyester $(80 / 20)$} \\
\hline Commercial paste & $4-5$ & $4-5$ & 4 & 4 & 4 & 4 & 4 & 4 & 1 & 15.64 \\
\hline $5 \%$ starch/chitosan & $4-5$ & 4 & 4 & 4 & 4 & 4 & 4 & 4 & 3 & 15.65 \\
\hline \multicolumn{11}{|c|}{ Polyester } \\
\hline Commercial paste & $4-5$ & $4-5$ & 4 & 4 & 4 & 4 & 4 & 4 & 1 & 18.62 \\
\hline 6\% Starch/chitosan & $4-5$ & $4-5$ & 4 & 4 & 4 & 4 & 4 & 4 & $3-4$ & 18.73 \\
\hline \multicolumn{11}{|c|}{ Polyamide } \\
\hline \multirow{2}{*}{ Commercial paste } & $4-5$ & 3 & 3 & 3 & 3 & 3 & 3 & 3 & 1 & 24.67 \\
\hline & $4-5$ & 4 & 3 & 3 & 3 & 3 & 3 & 3 & $3-4$ & 18.49 \\
\hline \multicolumn{11}{|c|}{ Wool } \\
\hline Commercial paste & 4 & 4 & 4 & 4 & 4 & 4 & 4 & 4 & 1 & 25.01 \\
\hline $6 \%$ Starch/chitosan & 4 & 3 & 4 & 4 & 4 & 4 & 4 & 4 & 3 & 25.00 \\
\hline
\end{tabular}

TABLE 7: Antibacterial activity of different printed fabrics.

\begin{tabular}{lcccc}
\hline \multirow{2}{*}{ Sample } & & \multicolumn{3}{c}{ Inhibition zone diameter $(\mathrm{mm} / \mathrm{mg}$ sample) } \\
& Bacillus subtilis $(G+)$ & Esherichia coli $(G-)$ & Staphylococcus aureus $(G+)$ & pseudomonas aeruginosa gram $(G-)$ \\
\hline Control & 0.0 & 0.0 & 0.0 & 0.0 \\
Cotton & 14 & 14 & 15 & 14 \\
Cotton/polyester & 15 & 15 & 15 & 16 \\
Viscose/polyester & 15 & 16 & 15 & 16 \\
wool & 16 & 16 & 15 & 16 \\
\hline
\end{tabular}




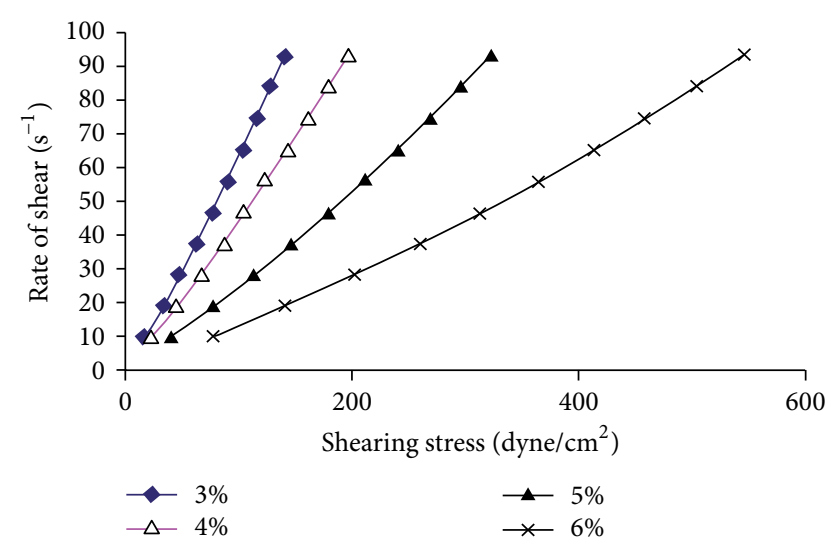

FIGURE 1: Rheograms of different concentrations of freshpreparedstarch/chitosan thickener.

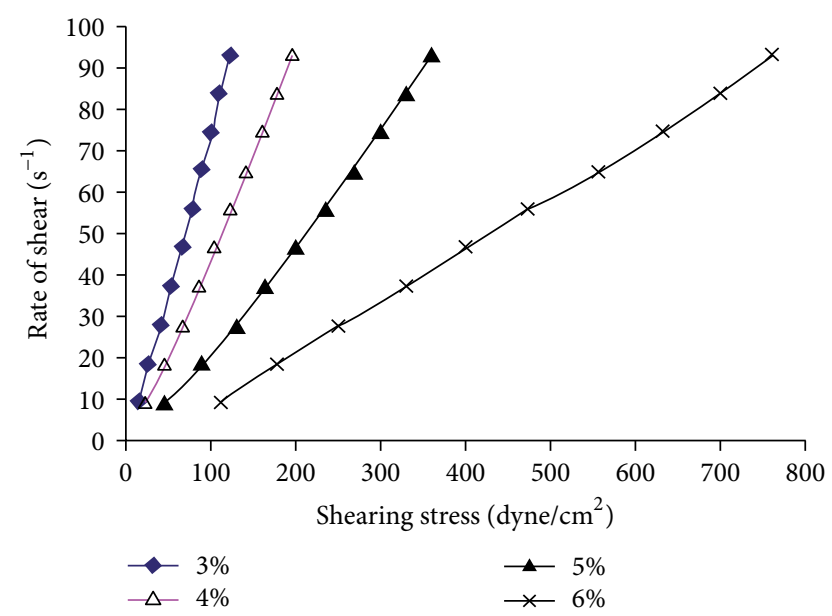

FIGURE 2: Rheograms of different concentrations of starch/chitosan thickener after storing for 24 hours.

the ascending and descending rheograms are coincident. This reveals the homogeneity of the molecular structure of the pastes which are amenable to rebuild themselves and retain their original state immediately after removal of the acting force, thereby exhibiting pseudoplastic behavior.

Figure 1 shows that, the location of the rheograms with respect to the rate of shear axis depends on the nature of the thickening agent used. As the concentration of starch increases the rheogram is located far from the rate of shear axis indicating an increase in the apparent viscosity.

Figure 2 represents the rheograms of the aforementioned pastes after storing for $24 \mathrm{~h}$. It is clear from the rheograms that storing has practically no effect on the rheological characteristics of these pastes where each of these pastes remains exhibiting non-Newtonian pseudoplastic behavior after storing.

The apparent viscosity at various rate of shear of the aforementioned pastes was calculated from the values of rate of shear. The results obtained are given in Tables 2 and 3. It is clear that the storing for $24 \mathrm{~h}$ does not affect so much the appearing viscosity of the prepared pastes.
3.5. Color Strength and Related Parameters. Chitosan has been proved to increase the rate of dye uptake and dye exhaustion of wool fabrics in the case of acid, reactive dyes and natural dye as henna $[5,23,24]$. However, combination of starch with chitosan to be used as thickening agent in textile printing has not been investigated so far. Therefore it has been taken up in the present study with natural dye. Thickeners act as a vehicle for the dye and during the fixation the dye transferred into the fabric then the thickener is washed off completely from the fabric. K/S value is directly proportional to the amount of dye present in the material and it can be used to evaluate the efficiency of new thickeners. The K/S values and the relative color strength $\%$ of Curcuma tinctoria printed samples are given in Table 4.

It is clear from Table 4, that the K/S and the relative color strength \% values of all the printed samples using starch/chitosan thickeners are higher than that of the standard samples. These results further affirm that chitosan increases the amount of Curcuma tinctoria uptake. This holds true in all printed samples despite the nature of fabric used and the $\%$ of starch in the thickener.

It is known that all natural dye have low affinity to synthetic fabrics and this was one of its drawback especially with the increase in production of synthetic fabrics and their blends. The K/S values of the printed synthetic fabrics and their blends reveal that the presence of this ratio of chitosan in the new thickeners has overcome this problem. Cotton/polyester printed samples achieved the highest relative color \% 598, where the K/S increases from 1.91 to 11.42 using $4 \%$ starch/chitosan thickener. The K/S of others synthetic printed fabrics (polyester and polyamide) increase from 0.98 to 5.12 and from 1.44 to 7.94 with relative color strength \% 523 and 551, respectively, using $5 \%$ starch/chitosan thickener. For natural fabric as wool the highest K/S was achieved by using 3\% starch/chitosan blend. These results refer that the highest K/S values have been achieved at different blends although the ratio of chitosan is constant, this may be due to the nature of the fabrics and the thickener viscosity.

To evaluate the color parameter and the color difference of printed fabrics with highest K/S value, CIE Lab system is used. Where $L$ refers to lightness-darkness values from 100 to 0 representing white to black, values run from negative (green) to positive (red) and $b$ values run from negative (blue) to positive (yellow), and the total color difference is given by $\Delta E$.

It can be seen from Table 5 that the $L$ values decrease in all the printed samples indicating that the sample becomes darker compared to that of the control sample. As seen from $\mathrm{a}$ and $\mathrm{b}$ values that the color hue changes to reddish yellow.

The color difference $(\Delta E)$ values are also given in Table 5 and it can be clearly seen that there is a significant color difference between the samples and the control samples though the dye concentration is constant.

The chroma is calculated as $\left(a^{2}+b^{2}\right)^{1 / 2}$ as the chromaticity increases, a color becomes more intense; as it decreases a color becomes dull and this is clear from Table 5 that the chroma of sample $\left(\mathrm{C}_{a b}\right)$ increased. 
3.6. Determination of Fastness Properties and Surface Roughness. It is clear from the data of Table 6 that with this new thickeners natural dye could print all kinds of fabrics under investigation with very good to excellent color fastness to rubbing, washing or perspiration. The notice of improvement is in the light fastness.

The surface properties of the antistatic-treated fabrics are very important because these fabrics are used mainly for garments in direct contact with human skin, that surface roughness has strong effect on the wearer comfort. Surface roughness results of cotton, polyester, polyamide, and blend fabrics are given in Table 6 . The results showed the same or slight increase in the surface roughness of the using chitosan/starch blend compared with the standard.

3.7. Antimicrobial Activity of Treated Fabrics. Early research describing the antimicrobial potential of chitin, chitosan, and their derivatives dated from the 1980-1990s [25]. Generally, recent data in the literature has the tendency to characterize chitosan as bacteriostatic rather than bactericidal.

Table 7 shows that the printed fabrics using chitosanstarch blend exhibit antimicrobial characteristics compared with the control sample.

\section{Conclusion}

Chitosan, which is a very useful nontoxic biopolymer, can be used as an effective antimicrobial finish and can also be used to increase the dye uptake of the fabrics. The new blends have definite rheological properties under varying shear stress during the entire printing process.

The addition of chitosan to gelatinous starch has twofold effects: nature dye has successfully printed all fabric with increase in the color strength and related parameters of the printed fabrics, and the other is that it produces antimicrobial fabrics. The fastness properties of these fabrics are good against washing, light and perspiration. Thus, a nontoxic, ecofriendly, multifunctional finish has been developed for using natural dye in printing all fabrics.

\section{Acknowledgment}

This work was supported by Dyeing, Printing and Auxiliaries Department, Textile Division, National Research centre.

\section{References}

[1] F. A. Nagia and R. S. R. EL-Mohamedy, "Dyeing of wool with natural anthraquinone dyes from Fusarium oxysporum," Dyes and Pigments, vol. 75, no. 3, pp. 550-555, 2007.

[2] T. Bechtold, A. Mahmud-Ali, and R. Mussak, "Natural dyes for textile dyeing: a comparison of methods to assess the quality of Canadian golden rod plant material," Dyes and Pigments, vol. 75, no. 2, pp. 287-293, 2007.

[3] M. Sundrarajan, A. Rukmani, R. Rajiv Gandhi, and S. Vigneshwaran, "Eco friendly modification of cotton using enzyme and chitosan for enhanced dyeability of curcuma longa," Journal of Chemical and Pharmaceutical Research, vol. 4, no. 3, pp. 1654-1660, 2012.
[4] B. N. Bandyopadhyay, G. N. Sheth, and M. M. Moni, "Application of chitosan in dyeing and finishing," Bombay Textile Research Association Scan, vol. 31, no. 1, pp. 5-12, 2001.

[5] S. H. Lim and S. M. Hudson, "Review of chitosan and its derivatives as antimicrobial agents and their uses as textile chemicals," Journal of Macromolecular Science, vol. 43, no. 2, pp. 223-269, 2003.

[6] R. Rajendran, R. Radhai, C. Balakumar, H. A. M. Ahamed, C. Vigneswaran, and K. Vaideki, "Synthesis and characterization of neem chitosan nanocomposites for development of antimicrobial cotton textiles," Journal of Engineered Fibers and Fabrics, vol. 7, no. 1, pp. 136-141, 2012.

[7] A. A. Tayel, S. H. Moussa, W. F. El-Tras, N. M. Elguindy, and K. Opwis, "Antimicrobial textile treated with chitosan from Aspergillus niger mycelial waste," International Journal of Biological Macromolecules, vol. 49, no. 2, pp. 241-245, 2011.

[8] S. Kittinaovarat, "Using chitosan for improving the dyeability of cotton fabrics with mangosteen rind dye," The Journal of Scientific Research Chulalongkorn University, vol. 29, pp. 155-164, 2004.

[9] S. Srisuk and K. Srikulkit, "Properties evaluation of some sodium nitrite chitosan-cotton fabric," Journal of Metals, Materials and Minerals, vol. 18, pp. 41-45, 2008.

[10] S. Mathew and T. E. Abraham, "Characterisation of ferulic acid incorporated starch-chitosan blend films," Food Hydrocolloids, vol. 22, no. 5, pp. 826-835, 2008.

[11] E. S. Abdou, K. S. A. Nagy, and M. Z. Elsabee, "Extraction and characterization of chitin and chitosan from local sources," Bioresource Technology, vol. 99, no. 5, pp. 1359-1367, 2008.

[12] A. Domard and M. Rinaudo, "Preparation and characterization of fully deacetylated chitosan," International Journal of Biological Macromolecules, vol. 5, no. 1, pp. 49-52, 1983.

[13] R. Ravindra, K. R. Krovvidi, and A. A. Khan, "Solubility parameter of chitin and chitosan," Carbohydrate Polymers, vol. 36, no. 2-3, pp. 121-127, 1998.

[14] P. N. Bhandari, R. S. Singhal, and D. D. Kale, "Effect of succinylation on the rheological profile of starch pastes," Carbohydrate Polymers, vol. 47, no. 4, pp. 365-371, 2002.

[15] AATCC, Technical Manual, Method, 36, (1972), 68, (1993).

[16] AATCC, Technical Manual, Method, 8, (1989), 68, 23(1993).

[17] AATCC, Technical Manual, Method, 15, (1989), 68, 30 (1993).

[18] AATCC, Technical Manual, Method, 16A, (1989), 68, 33 (1993).

[19] National Committee for Clinical Laboratory Standards, "Reference Method for Broth Dilution Antifungal Susceptibility Testing of Filamentous Fungi: Approved Standard M38-A. NCCLS," Wayne, Pa, USA, 2002.

[20] J. Nunthanid, S. Puttipipatkhachorn, K. Yamamoto, and G. E. Peck, "Physical properties and molecular behavior of chitosan films," Drug Development and Industrial Pharmacy, vol. 27, no. 2, pp. 143-157, 2001.

[21] X. L. Shen, J. M. Wu, Y. Chen, and G. Zhao, "Antimicrobial and physical properties of sweet potato starch films incorporated with potassium sorbate or chitosan," Food Hydrocolloids, vol. 24, no. 4, pp. 285-290, 2010.

[22] M. Lavertu, Z. Xia, A. N. Serreqi et al., "A validated 1 H NMR method for the determination of the degree of deacetylation of chitosan," Journal of Pharmaceutical and Biomedical Analysis, vol. 32, no. 6, pp. 1149-1158, 2003.

[23] D. R. Stephen and X. Yulin, "Improving the dye ability of wool by treatment with chitosan," Journal of the Society of Dyers and Colorists, vol. 110, pp. 24-29, 1994. 
[24] V. R. G. Dev, J. Venugopal, S. Sudha, G. Deepika, and S. Ramakrishna, "Dyeing and antimicrobial characteristics of chitosan treated wool fabrics with henna dye," Carbohydrate Polymers, vol. 75, no. 4, pp. 646-650, 2009.

[25] L. A. Hadwiger, D. G. Kendra, B. W. Fristensky, and W. Wagoner, "Chitosan both activated genes in plants and inhibits RNA synthesis in fungi," in Chitin in Nature and Technology, R. A. A. Muzzarelli, C. Jeuniaux, and G. W. Gooday, Eds., Plenum, New York, NY, USA, 1981. 

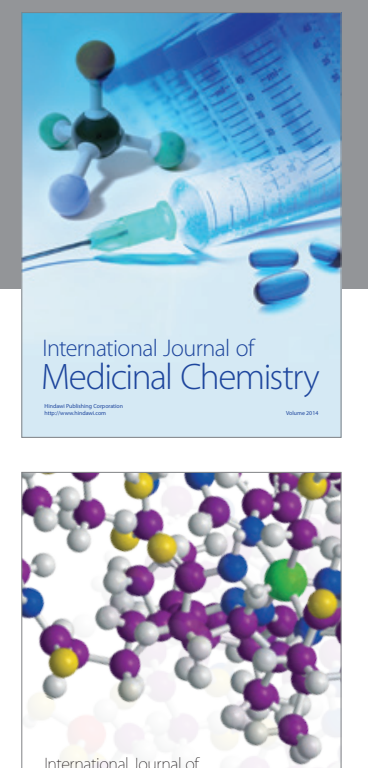

\section{Carbohydrate} Chemistry

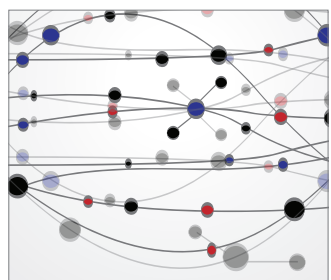

The Scientific World Journal
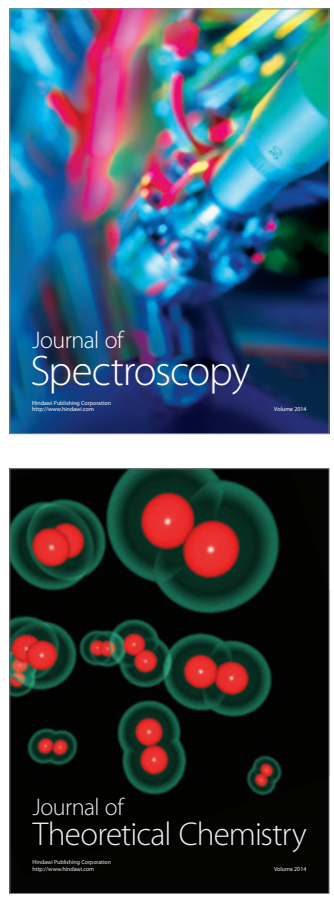
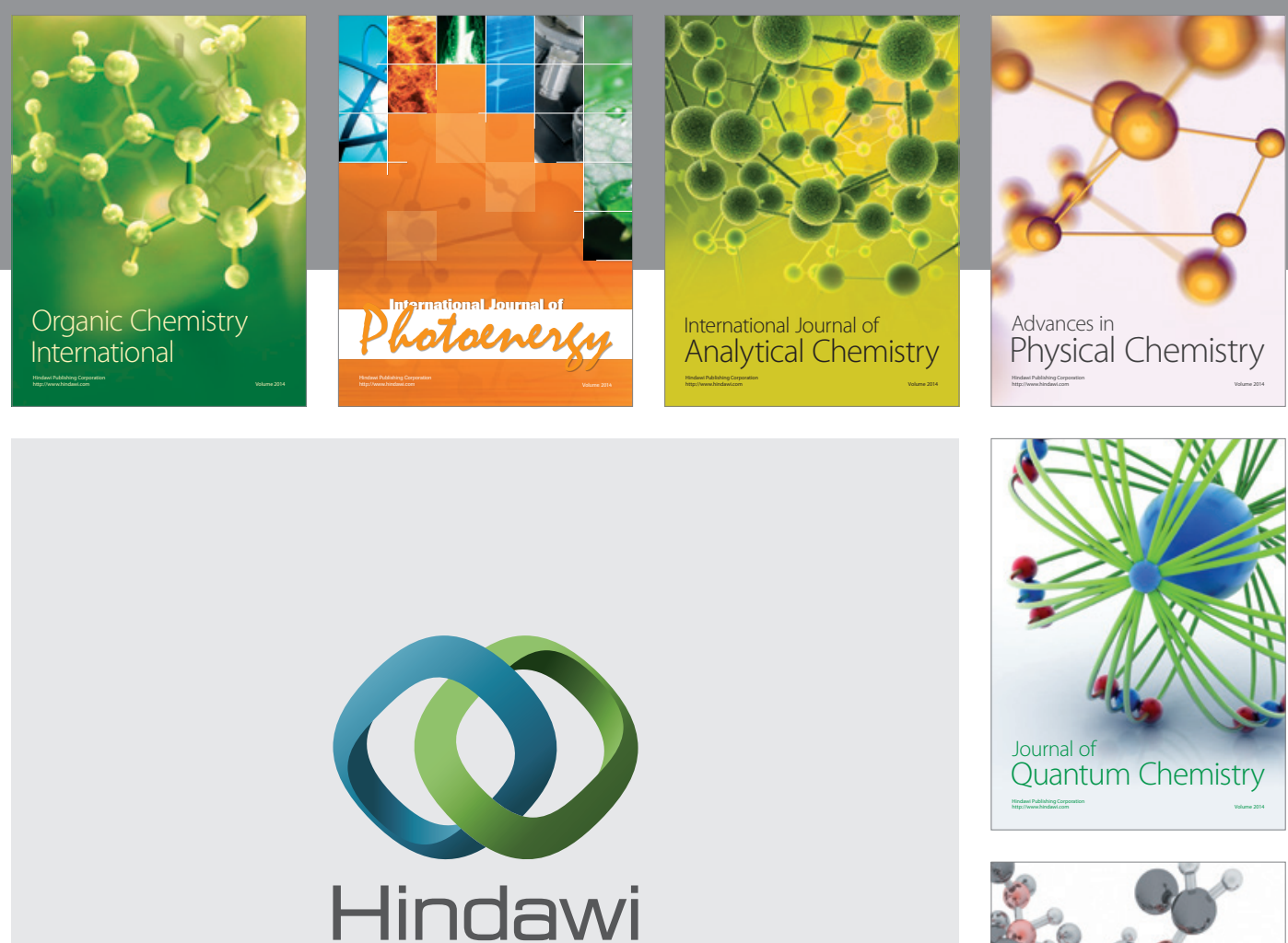

Submit your manuscripts at

http://www.hindawi.com

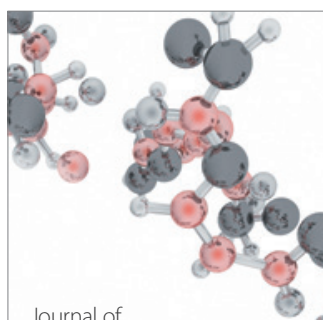

Analytical Methods

in Chemistry

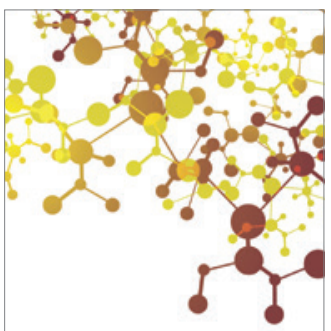

Journal of

Applied Chemistry

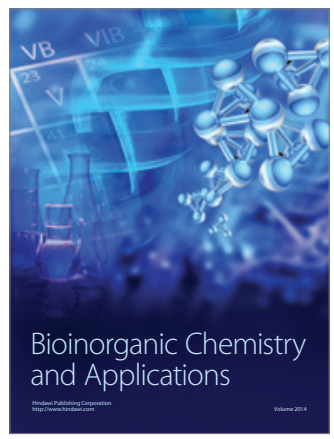

Inorganic Chemistry
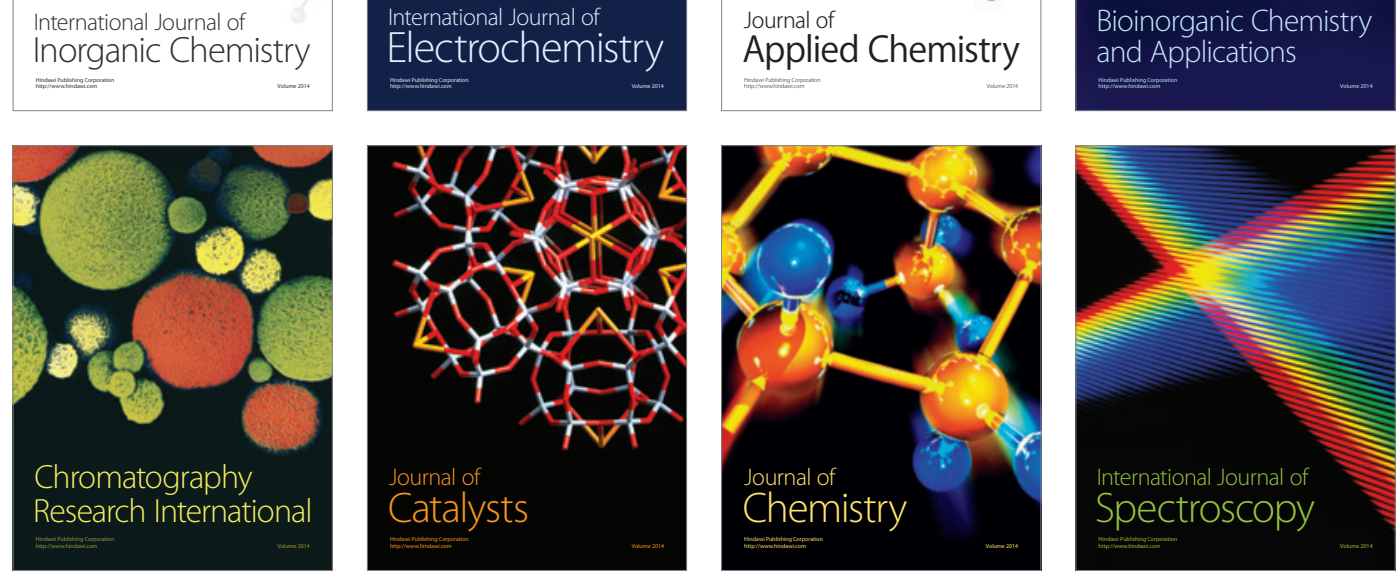